\title{
CAPACIDAD DE DESARROLLO DE OVOCITOS VITRIFICADOS EN ESTADÍO INMADURO Y MADURO EN BOVINOS
}

\author{
Development competence of vitrified oocytes at immature and mature stage in \\ bovine
}

Yander M. Briceño', Jenin V.Cortez', IlseS.Cayo ${ }^{1,2}$

http://dx.doi.org/10.18548/aspe/0002.5

Laboratorio de Biotecnología Animal, Reproducción y Mejoramiento Genético, Facultad de Ingeniería Zootecnista, Agronegocios y Biotecnología

2 Universidad Nacional Toribio Rodríguez de Mendoza, Chachapoyas, Departamento Amazonas, Perú

E-mail: mavila.briceño@untrm.edu.pe

\section{RESUMEN}

El objetivo de este trabajo fue estudiar el efecto de la vitrificación de ovocitos inmaduros y madurados in vitro sobre su viabilidad postdescongelamiento. Los ovocitos fueron aspirados de ovarios colectados del centro de beneficio de la ciudad de Chachapoyas, luego fueron vitrificados en estadío inmaduros (IM) o madurados in vitro (MIV), separadamente. Para evaluar su viabilidad post descongelamiento, se determinó la actividad enzimática y el daño al ADN con fluorescein diacetate (FDA) y propidium iodide (PI); respectivamente, y el potencial de desarrollo embrionario por partenogénesis. El porcentaje de ovocitos con actividad enzimática en IM y MIV fue de 34,46\% y 67, 16\%, y la producción de blastocisto fue de $4,75 \%$ y $10,17 \%$, respectivamente y la producción de blastocistos sin la vitrificación fue de 38,76\%. Los estudios continúan realizándose.

Palabras clave: Vitrificación, cryotop, viabilidad, blastocistos.

\section{ABSTRACT}

The aim of this research was to study the vitrification of immature and in vitro matured oocytes on their viability after thawing. The oocytes were aspirated from ovaries collected from a local abattoir, then they were vitrified in immature stage or in vitro matured (MIV) stages, separately. To evaluate their viability after thawing, the enzymatic activity and DNA damage were examined with fluorescein diacetate (FDA) and propidium iodide $(\mathrm{PI})$, respectively, and their developmental competence through parthenogenesis. The percentage of oocytes with enzymatic activity in IM and MIV oocytes were $34.46 \%$ and $67.16 \%$, and their blastocyst production were $4.75 \%$ and $10.17 \%$, respectively and the blastocyst production of non vitrified oocyte was $38.76 \%$. Studies are still being performed.

Keywords: Vitrification, cryotop, viability, blastocysts 


\section{INTRODUCCION.}

Según Fernández et al. (2012), la posibilidad de criopreservar material genético mediante la vitrificación de gametos brinda alternativas para la conservación de germoplasma. Sin embargo, en la actualidad, la ausencia de tecnologías eficaces para la criopreservación de ovocitos representa una de las causas que dan lugar a la pérdida de la diversidad genética. Más aún, obstaculiza la eficiencia de las tecnologías reproductivas.

Existen diversas metodologías empleadas para la criopreservación de material biológico; una de las alternativas es la vitrificación, la que se define como la transición de las soluciones acuosas de un estado líquido a un estado vítreo sólido sin la formación de cristales, aunque su estructura molecular sea la de un líquido extremadamente viscoso (estado vítreo)(Crister, 1997).

El proceso de vitrificación requiere de la presencia de una alta concentración de crioprotectores, y al mismo tiempo protocolos que minimicen el daño celular provocado por el estrés osmótico o la toxicidad química provocada por dichas concentraciones utilizadas. Por ello, el principal objetivo de un protocolo de vitrificación debe ser la disminución de la toxicidad sin pérdida de efectividad de los agentes crioprotectores. Para reducir la toxicidad de las soluciones crioprotectoras se han desarrollado diferentes protocolos donde se combinan uno o varios crioprotectores intra y extracelulares (Albarracín, 2005).

Investigaciones relacionadas al tema vienen siendo desarrolladas, pero hasta el momento, no existen protocolos exitosos. Por ello, se crea la necesidad de realizar estudios para definir un protocolo de criopreservación de ovocitos, el cual al ser validada permitirá optimizar y aprovechar los germoplasmas y núcleos de alto valor genético.

\section{MATERIALES Y MÉTODOS}

Todos los reactivos y medios de cultivo usados fueron de SIGMA-ALDRICH (USA) a menos que se especifique lo contrario.

\section{Obtención y selección de los ovocitos}

Los ovarios se transportaron del centro de beneficio de Chachapoyas-Amazonas, en un recipiente isotérmico conteniendo cloruro de sodio al $0.9 \%$ (wt/vol) con $0.025 \mathrm{mg} / \mathrm{ml}$ de estreptomicina, temperado a $37^{\circ} \mathrm{C}$.
Los complejos cúmulos ovocitos (COCs) se aspiraron de folículos de $2.7 \mathrm{~mm}$ con una jeringa de $10 \mathrm{ml}$ y una aguja de $18 \mathrm{G}$. Los COCs fueron seleccionados usando un estereoscopio (Olympus, Japón) y sólo los que presentaron un citoplasma homogéneo y al menos dos capas completas de células del cúmulus fueron usados.

\section{Maduración in vitro}

Los COC's se cultivaron en grupos de 25 , en una placa de cuatro pocillos de $500 \mu \mathrm{l}$ durante 24 horas a una temperatura de $38.5^{\circ} \mathrm{C}$ y $5 \%$ de $\mathrm{CO} 2$, con aire saturado de humedad en medio de maduración TCM199 suplementado con $0.1 \mathrm{mg} / \mathrm{ml}$ de L-Glutamina, $0.25 \mathrm{mg} / \mathrm{ml}$ de piruvato de sodio, $0.01 \mathrm{U} / \mathrm{ml}$ de Hormona Folículo Estimulante (FSH), $0.01 \mathrm{U} / \mathrm{ml}$ de Hormona Luteizante $(\mathrm{LH}), 50 \mu \mathrm{g} / \mathrm{ml}$ de gentamicina, $1 \mu \mathrm{g} / \mathrm{ml}$ de $17 \beta$ estradiol y $10 \%$ de Suero Fetal Bovino (SFB). El grupo de COCs vitrificados en IM, se conservaron en nitrógeno líquido por 3 días. Luego fueron madurados in vitro post-descongelamiento, para evaluar el estadío alcanzado. La metodología empleada se describe líneas abajo.

\section{Activación partenogénica}

Para la activación partenogénica los COCs madurados in vitro fueron denudados con $0.5 \mathrm{mg} / \mathrm{ml}$ de hyaluronidasa en TCM-199 HEPES en vórtex por 6 minutos; luego se activaron en etanol al 7\% en TCM199 HEPES por 5 minutos, lavados con TCM-199 conteniendo $10 \%$ SFB y finalmente incubados por 5 horas a $38.5^{\circ} \mathrm{C}$ y $5 \%$ de $\mathrm{CO} 2$ en medio TCM-199 conteniendo $10 \%$ SFB suplementado con $5 \mu \mathrm{g} / \mathrm{ml}$ de Cytochalasin B (Cito B) y $10 \mu \mathrm{g} / \mathrm{ml}$ de Cicloheximide (CHX).

\section{Cultivo in vitro}

Se cultivaron los cigotos en grupos de 25 en una placa de cuatro pocillos durante 7 días a $38.5^{\circ} \mathrm{C}$, con mezcla de gases, utilizando el medio SOF base (Vajta et al., 2000) suplementado con $0.044 \mathrm{~g} / \mathrm{l}$ de piruvato de sodio, $0.039 \mathrm{~g} / \mathrm{l}$ de L-glutamina, $3.0 \mathrm{mg} / \mathrm{ml}$ de Suero Albumina Bovina (BSA-FAF), $1 \mathrm{X}$ de amino ácidos esenciales, $1 X$ de amino ácidos no esenciales, $10 \mathrm{mg} / \mathrm{ml}$ de $E G F, 0.1 \mathrm{mg} / \mathrm{mL}$ de ácido cítrico, $0.5 \mathrm{mg} / \mathrm{ml}$ de myo-inositol, $50 \mu \mathrm{g} / \mathrm{ml}$ de gentamicina y $2 \%$ de SFB. Se consideraron ovocitos degenerados a aquellos que no presentaron división celular y tenían poco o nada de contenido citoplasmático.

\section{Vitrificación y descongelamiento de ovocitos}

Los COC's fueron sumergidos en una solución equilibrante (SE) por 3 minutos. La SE consistió en $7,5 \%$ de Etileno Glicol (EG) y $7.5 \%$ de Dimetil Sulfóxido (DMSO) en solución base (SB). La SB estuvo compuesta por TCM-199 HEPES y $20 \%$ de SFB. 
Posteriormente, los COCs fueron expuestos por 1 minuto a la solución de vitrificación (SV), que consistió en $15 \%$ de EG, $15 \%$ de DMSO y $0.5 \mathrm{M}$ de sucrosa en $\mathrm{SB}$. Finalmente, los COCs fueron colocados en los cryotop's y sumergidos en nitrógeno líquido. Después de tres días, se descongelaron. La descongelación se realizó sumergiendo el cryotop directamente en la solución de descongelamiento (SD) por 30 segundos a $40^{\circ} \mathrm{C}$ (1 $1 \mathrm{M}$ de sucrosa en solución base), para posteriormente exponerlos a la solución de dilución (SDi) por 5 minutos a $40^{\circ} \mathrm{C}(0.5 \mathrm{M}$ sucrosa en solución base). Finalmente los ovocitos fueron lavados tres veces en SB dejándolos reposar 5 minutos entre cada lavado. Para esta investigación, se vitrificaron ovocitos inmaduros (IM) y ovocitos madurados in vitro (MIV). Para el caso de los COC's madurados, éstos fueron denudados hasta dejarlos con al menos dos capas homogéneas de células de cúmulus antes de pasar al proceso de vitrificación.

Evaluación de la viabilidad de los ovocitos postdescongelamiento

La viabilidad de los ovocitos post-descongelamiento fue medida a través de la tinción con propidium iodide (PI) y Fluorescein diacetate (FDA) ya que estos indican el daño al ADN y la actividad enzimática, respectivamente. Los ovocitos considerados viables fueron aquellos que emitían un intenso verde fluorescente. Los ovocitos considerados como no viables fueron aquellos que no emitían fluorescencia verde y presentaban áreas con fluorescencia roja. Para ello, los ovocitos se denudaron con un vórtex por 6 minutos en medio de manipulación que contenía TCM199 HEPES, $10 \%$ de SFB y $0.1 \%$ de gentamicina. Luego, fueron colocados en medio de tinción compuesto por PBS-PVA suplementado con $1.0 \mathrm{mg} / \mathrm{ml}$ de $\mathrm{Pl}$ y $25 \mathrm{mg} / \mathrm{ml}$ de FDA y llevados a incubación por 10 minutos luego del cual, fueron examinados con ayuda de un microscopio invertido (Olympus, Japón) con fluorescencia.

\section{Análisis estadístico}

La diferencia entre los promedios de la actividad enzimática de los ovocitos MIV, IM y control se realizó con una prueba de homogeneidad de varianzas (prueba de Levene). Con el análisis de varianza (ANOVA) se evaluó la diferencia entre promedios de mórulas y blastocitos obtenidos en los grupos experimentales con un $a=5 \%$. La prueba de Dunnet se usó para determinar en qué par de tratamientos hay mayor diferencia significativa con un $a=5 \%$.

\section{RESULTADOS}

La Tabla 1 muestra que el $67.16 \%$ de los ovocitos madurados in vitro sobrevivieron al proceso de vitrificación, comparados a los inmaduros; donde solo el $34.46 \%$ resultaron viables.

Tabla 1. Viabilidad de ovocitos vitrificados y descongelados.

\begin{tabular}{lccc}
\hline Grupo & $\mathrm{n}$ & $\begin{array}{l}\text { Viables } \\
\mathrm{n}(\%)\end{array}$ & $\begin{array}{c}\text { No viables } \\
\mathrm{n}(\%)\end{array}$ \\
\hline Vitrificados maduros & 134 & 90 & 44 \\
(24h IVM & & $(67.2) \mathrm{a}$ & $(32.8)$ \\
\hline Vitrificados & 148 & 51 & 97 \\
inmaduros (Oh IVM) & & $(34.5) \mathrm{b}$ & $(65.5)$ \\
\hline
\end{tabular}

$a, b$; letras diferentes significa que existen diferencias significativas $(p<0.05)$

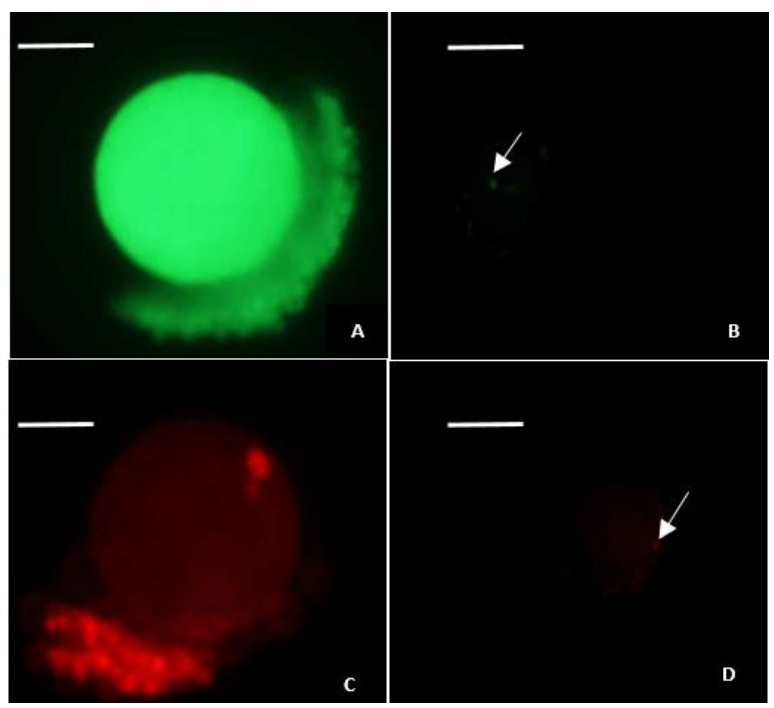

Figura 1. Determinación de la viabilidad postdescongelamiento con fluorescencia. A. Ovocito viable; la tinción verde indica actividad enzimáticaviabilidad. B. Ovocito no viable; trazas de actividad enzimática, probablemente de células del cúmulus. C. Ovocito no viable; la tinción roja indica daño del ADN tanto en el ovocito como en las células del cúmulus. D. Ovocito viable; sin daño probable del ADN. Puntos rojos indican daño del $A D N$ en algunas células del cúmulus. La barra indica $50 \mu \mathrm{m}$.

La Tabla 2 muestra la producción de embriones partenogénicos post descongelamiento, a partir de COCs vitrificados (Los COCs inmaduros pasaron por un proceso de maduración in vitro post descongelamiento). Se observa que el porcentaje de mórulas fue de $1,48 \%$ y $0,83 \%$, y la producción de blastocistos fue de $10,17 \%$ y $4,75 \%$, para ovocitos 
madurados in vitro e inmaduros, respectivamente. Y la producción de blastocistos sin proceso previo de vitrificación fue de 38,76\%.

Tabla 2. Desarrollo de embriones partenogénicos procedentes de ovocitos vitrificados, post 7 días de activación.

\begin{tabular}{lcccc}
\hline Grupo & $\mathrm{n}$ & $\begin{array}{c}<32 \text { cel } \\
\mathrm{n}(\%)\end{array}$ & $\begin{array}{c}\text { Mórulas } \\
\mathrm{n}(\%)\end{array}$ & $\begin{array}{c}\text { Blastocistos, } \\
\mathrm{n}(\%)\end{array}$ \\
\hline $\begin{array}{l}\text { Vitrificados } \\
\text { maduros (24h }\end{array}$ & 472 & $\begin{array}{c}72 \\
(15.3)\end{array}$ & $\begin{array}{c}7 \\
(1.5) \mathrm{a}\end{array}$ & $\begin{array}{c}48 \\
(10.2) \mathrm{b}\end{array}$ \\
$\begin{array}{l}\text { IVM } \\
\text { Vitrificados }\end{array}$ & 484 & $\begin{array}{c}601 \\
(12.4)\end{array}$ & $\begin{array}{c}4 \\
(0.8) \mathrm{a}\end{array}$ & $\begin{array}{c}23 \\
(4.8) \mathrm{b}\end{array}$ \\
$\begin{array}{l}\text { inmaduros (Oh } \\
\text { IVM) }\end{array}$ & & & & \\
\hline $\begin{array}{l}\text { Control } \\
\text { (sin }\end{array}$ & 516 & $\begin{array}{c}105 \\
(20.4)\end{array}$ & $\begin{array}{c}42 \\
(8.1)\end{array}$ & $\begin{array}{c}200 \\
(38.8)\end{array}$
\end{tabular}

vitrificación)

$a, b$; letras diferentes significa que existen diferencias significativas $(p<0.05)$

\section{DISCUSIÓN}

Se sabe que la supervivencia del ovocito bovino difiere de acuerdo a la duración de la exposición al crioprotector, la concentración y la forma de remover el mismo (Fabbri et al., 2000). Otro factor que influye es el estadío de desarrollo en el cuál se encuentran al momento de la vitrificación (Shaw et al., 2000). En suma a ello, se consideran ovocitos viables a aquellos que no presentan lisis celular, con una membrana celular intacta y citoplasma homogéneo; de lo contrario son clasificados como degenerados (Otoi et al., 1995).

Existen además diversas técnicas de evaluación de supervivencia o viabilidad como aquellas que emplean tinciones con propidium iodide y fluorescein diacetate, que identifican daño del ADN y actividad enzimática, respectivamente (Men et al., 2003; Somfai et al., 2007). En nuestro trabajo se emplearon estas dos últimas tinciones, y observamos que los ovocitos en MIV sobrevivieron mejor a la vitrificación (67.16\%) comparados a los de estadío de IM (34.46\%). Estos resultados son similares a los reportados por Fuku et al. (1995) quienes observaron que los ovocitos madurados in vitro (MIV) pueden ser criopreservados manteniendo su viabilidad después de la descongelación y lograr una tasa de segmentación del $6,7 \%$.

La supervivencia $\circ$ mantenimiento de la viabilidad podría deberse a que los ovocitos en MIV presentan el citoesqueleto organizado, han completado su crecimiento y su maduración nuclear y citoplásmica (Arav et al., 1993; Otoi et al., 1995), los cuales son necesarias para la producción de embriones. En nuestro estudio, los ovocitos MIV, no solo lograron un mayor porcentaje de supervivencia post descongelamiento, sino también, mayor producción de embriones partenogénicos. Esto nos sugiere que los ovocitos MIV tienen mayor oportunidad de sobrevivir al proceso de vitrificación.

\section{CONCLUSIÓN}

Los ovocitos vitrificados en estado madurado post 24 en medio de maduración, son más tolerantes a la vitrificación. Pero, tienen una menor viabilidad que los ovocitos control

\section{REFERENCIAS}

- Albarracín J. Vitrificación de ovocitos bovinos mediante la técnica Open Pulled Straw: Estudio estructural de cromosomas, microtúbulos y microfilamentos y posterior desarrollo embrionario in vitro. Tesis doctoral. Bellaterra (Barcelona). Universidad Autónoma de Barcelona. 2005. 133p.

- Arar A, Shehu D and Mattioli M. Osmotic and cytotoxic study of vitrification of immature bovine oocytes. J Reprod Fertil 1993. 99(2):353-358.

- Critser, JK; Agca, Y y Gunasena, KT. The cryobiology of mammalian oocytes. pp 24. En: Albarracín Monje, J. 2005. Vitrificación de ovocitos bovinos mediante la técnica Open Pulled Straw: Estudio estructural de cromosomas, microtúbulos y microfilamentos y posterior desarrollo embrionario in vitro. Tesis doctoral. Bellaterra (Barcelona). Universidad Autónoma de Barcelona. 1997,133p.

- Fabbri R, Porcu E, Marsella T, Primavera M, Rocchetta G, Ciotti P, Magrini O, Saracchioli N, Venturoli S, Flamigni C. Thechnical aspects of oocyte cryopreservation. Molecular and Cellular Endocrinology 2000. 169: 39-42.

- Fernandez F. Viabilidad de ovocitos porcinos inmaduros y madurados in vitro vitrificados con etilén glicol y trehalosa. Revista de Salud Animal (México). Universidad Autónoma Metropolitana de Xochimilco. 2012, 34 (1): 46-52.

- Fuku E, Xia L, Downey BR. Ultrastructural changes in bovino oocytes cryopreserved by vitrification. Cryobiology, 1995, 32:139-156.

- Men H, Monson R, Parrish J, Rutledge J. Degeneration of cryopreserved bovine oocyte vía apoptosis during subsequent culture. Cryobiology 2003; 47: 73-81. 
- Otoi T, Yamamoto K, Koyama N, Suzuki T. In vitro Fertilization and developmental of immature and mature bovine oocyte cryopreserved by ethylene glycol with sucrose. Cryobiology 1995, 32: 455460.

- Shaw J, Oranratnachai A, Trounson A. Fundamental cryobiology of mammalian oocytes and ovarian tissue. Theriogenology 2000; 53: 5972.

- Somfai T, Ozawa M, Noguchi J, Kaneko H, Kuriani NW, Farhudin M, Dinnyés A, Nagai T, Kikuchi K. Developmental competence of in vitrofertilized porcine oocytes after in vitro maturation and solid surface vitrification: effect of cryopreservation on oocyte antioxidative system and cell cycle stage. Cryobiology. 2007; 55:115-126.

- Vajta G, Peura TT, Holm P, Páldi A, Greve T, Trounson AO, Callesen $\mathrm{H}$. New method for culture of zona - included or zona free embryos: the wellof-the-well (WOW) system. Mol Reprod Dev. 2000. 55:256-264. 